\title{
Homicídios masculinos na Região Metropolitana de São Paulo entre 1979 e 1998: uma abordagem pictórica
}

\author{
Male homicide in Greater Metropolitan São Paulo: \\ a pictorial approach
}

Ricardo Cordeiro 1

Maria Rita Camargo Donalisio 2

\footnotetext{
1 Departamento de Saúde Pública, Faculdade de Medicina de Botucatu, Universidade

Estadual Paulista. C. P. 543, Botucatu, SP 18618-970, Brasil. cordeiro@fmb.unesp.br

2 Departamento de Medicina Preventiva e Social, Faculdade de Ciências Médicas, Universidade Estadual de Campinas. C. P. 6111, Campinas, SP 13093-970, Brasil. donalis@dglnet.com.br
}

\begin{abstract}
Homicide has become a major social problem in Brazil in the last two decades. In Greater Metropolitan São Paulo, Southeast Brazil, the proportional incidence of male homicides increased from 35 to 121 (x 10-5) from 1979 to 1998. This study presents the trend in this phenomenon using a set of three-dimensional figures. We show both the absolute number and proportional incidence of male deaths by homicide and the natural logarithm of the male/female relative risk of homicide for Greater Metropolitan São Paulo from 1979 to 1998. Seven 3D figures show the homicide trend by age, sex, and year. The figures show the main trends in homicide distribution in the male population during the study period: a clear predominance among adolescents and young adults, a systematic and sharp increase in that same age range, a systematic spread to the lower (below-18) and higher (above-30) age groups, and a non-negligible incidence above the age of 40.
\end{abstract}

Key words Homicide; Incidence; Violence

Resumo Os homicídios tornaram-se um grave problema social no Brasil nas últimas duas décadas, com repercussões em diversas áreas. O objetivo deste estudo é representar por imagens tridimensionais a evolução dos homicídios no sexo masculino, durante os últimos vinte anos, na Região Metropolitana de São Paulo. São apresentados o número absoluto e a proporção de incidência de óbitos masculinos causados por homicídios, bem como o logaritmo natural do risco relativo masculino/feminino de óbito por homicídio, na Região Metropolitana de São Paulo, entre 1979 e 1998. A proporção de incidência de óbitos por homicídios no sexo masculino cresceu de 35 para 121 (x 10-5) na região e período estudados. São apresentadas sete figuras tridimensionais que, em seu conjunto, situam a evolução deste fenômeno de acordo com faixa etária, ano calendário e sexo. As figuras apresentadas permitem facilmente visualizar as quatro principais características dos homicídios entre a população masculina: nítida predominância entre adolescente e adultos jovens; aumento consistente e acentuado ano a ano; espraiamento tanto para as menores idades (abaixo dos 18) quanto para as maiores (acima dos trinta); e manutenção de incidência elevada nas idades superiores a quarenta anos no final do período estudado.

Palavras-chave Homicídios; Incidência; Violência 


\section{Introdução}

A preocupação com a identificação e quantificação sistemática das mortes decorrentes de violência e acidentes surge antes do nascimento da epidemiologia. Em 1662, Graunt (1939) publica a primeira classificação de causas de morte de que se tem notícia, onde estas são sistematizadas em 83 categorias, dentre elas algumas correspondentes a causas externas de óbitos. Em 1855, William Farr apresenta em Paris ao 2o Congresso Internacional de Estatística uma classificação de causas de morte reunidas em cinco grandes grupos, sendo um deles "doenças que são o resultado direto de violências" (OMS, 1994). Esta iniciativa influenciou a Classificação de Causas de Morte de Bertillon, de 1893, que, por sua vez, foi a base para o desenvolvimento da Classificação Internacional de Causas de Morte e de Doenças durante todo o século XX. Da primeira (1900) à nona (1975) revisão, o número de categorias de causas externas cresceu de forma acentuada, estando elas atualmente agrupadas nos capítulos XIX e XX da 10a Revisão da Classificação Internacional de Doenças, publicada em 1994 (OMS, 1994).

$\mathrm{O}$ detalhamento crescente dispensado às causas externas de óbito acompanhou a complexidade que estas ganharam ao longo do tempo. Paralelamente ao processo de industrialização, cresceu a diversidade de óbitos não naturais (Mello-Jorge \& Laurenti, 1997), que passaram a apresentarem-se também como intoxicações por novas substâncias utilizadas na indústria, acidentes automobilísticos, óbitos decorrentes de armamento químico, radiativo e bacteriano, acidentes da aviação, etc.

A Organização Mundial de Saúde (OMS) estimou em $7 \%$ a média da mortalidade proporcional por causas externas no mundo em 1985 (Lopes, 1993). Atualmente, na maioria dos países, esse grupo de causas figura entre os cinco mais importantes.

Além do sofrimento da vítima e dos familiares, acarretando grande ônus psicossocial à comunidade, a mortalidade por causas violentas consome recursos de forma concentrada, relacionados a internações hospitalares, tratamentos intensivos, medicamentos e exames complementares. Os custos indiretos se referem inclusive à perda de produtividade do trabalhador afastado do serviço (Iunes, 1997).

No Brasil, as causas externas ocupavam o quarto lugar entre os grupos de óbito mais importantes em 1980, passando ao segundo posto em números absolutos ao final da década (Souza \& Minayo, 1995). Entretanto, tratandose de um grupo de causas que afetam princi- palmente a população jovem, as causas externas atingem o primeiro lugar em importância quando se analisam anos potenciais de vida perdidos (Reichenhein \& Werneck, 1994).

O grande aumento da mortalidade por causas não naturais no país segue tendência internacional, porém as regiões metropolitanas a expressam de forma mais evidente, embora alguns autores identifiquem a tendência à interiorização destes óbitos (Szwarcwald \& Castilho, 1998). Observa-se o predomínio dos homicídios, particularmente nos grandes aglomerados urbanos brasileiros nas últimas duas décadas (Mello-Jorge et al., 1997]. Estes, dentre os óbitos por causas externas, além de predominarem amplamente, também compõem o grupo de óbitos cuja incidência mais cresceu desde o início dos anos 80 no Brasil (Minayo, 1994).

Na Região Metropolitana de São Paulo (RMSP), um dos quatro maiores aglomerados urbanos do mundo, os homicídios estendidos (definidos em Material e método) foram responsáveis por 2.410 óbitos no ano de 1979. A análise dos dados aqui apresentados permite identificar que nos vinte anos subseqüentes foram assassinados 130.761 moradores da RMSP, em sua maioria adolescentes e adultos jovens, sendo $92 \%$ deles do sexo masculino. Apenas no ano de 1998, o número de homicídios na RMSP foi 10.898, o que correspondeu a um aumento de $352 \%$ em relação a 1979 (ao passo que a população aumentou $43 \%$ no período), mais do que triplicando a incidência bruta de homicídios.

Os homicídios têm se configurado como uma verdadeira epidemia, um grave problema social com repercussões em diversas áreas, inclusive na saúde pública. A discussão das causas desse fenômeno transcende os limites deste estudo, cujo objetivo restringe-se a representar por imagens a evolução dos homicídios no sexo masculino durante os últimos vinte anos na RMSP, como mais um instrumento para a compreensão da dinâmica das mortes por causas externas.

\section{Material e método}

A região estudada é a RMSP, que compreende 38 municípios (Fundação SEADE, 1999): Arujá, Barueri, Biritiba-Mirim, Caieiras, Cajamar, Carapicuiba, Cotia, Diadema, Embú, Embú-Guaçu, Ferraz de Vasconcelos, Francisco Morato, Franco da Rocha, Guararema, Guarulhos, Itapecirica da Serra, Itapevi, Itaquaquecetuba, Jandira, Mairiporã, Mauá, Mogi das Cruzes, Osasco, Pirapora do Bom Jesus, Poá, Ribeirão 
Pires, Rio Grande da Serra, Salesópolis, Santa Isabel, Santana do Parnaíba, Santo André, São Bernardo do Campo, São Caetano do Sul, São Lourenço da Serra, São Paulo, Suzano, Taboão da Serra e Vargem Grande Paulista. O período estudado está compreendido entre 1o de janeiro de 1979 e 31 de dezembro de 1998, abrangendo vinte anos.

Neste estudo utilizou-se a categoria estendida de homicídios, que significa o grupo de causas básicas de óbito decorrentes de homicídios, lesões infligidas pela polícia e lesões de intencionalidade ignorada ou não especificada. Estas causas correspondem aos códigos E960 a E989 na 9a Revisão da Classificação Internacional de Doenças (OMS, 1985) e aos códigos X85 a Y35 (excetuando-se os códigos Y06 e Y07) na 10a Revisão (OMS, 1994). Utilizou-se aqui esta categoria ampliada pois os homicídios registrados nos atestados de óbito estão subestimados quando comparados a outras fontes de informação, deixando de fora grande contingente de agressões por armas de fogo de intencionalidade ignorada e outras violências, que quando melhor examinadas são classificadas como homicídios. Alguns autores têm chamado atenção para essas distorções dos registros de óbitos e proposto essa estratégia para diminuir os erros na interpretação das estatísticas deste grupo de mortes (Mello-Jorge, 1990; Minayo \& Souza, 1993].

São apresentadas figuras mostrando o número absoluto e a proporção de incidência ( $\mathrm{x}$ 105) (Rottman \& Greenland, 1998) de óbitos devidos a homicídios no sexo masculino. Para comparar-se visualmente a incidência de homicídios entre homens com a incidência entre mulheres, apresenta-se o logaritmo natural da razão entre a proporção de incidência de homicídios em homens e em mulheres, o que corresponde ao risco relativo masculino/feminino de óbito por homicídio estendido, na região e período estudados. Na figura apresentada, superfície obtida com a técnica de smoothing spline (Green \& Silverman, 1994), utilizou-se a transformação logarítmica do risco relativo para facilitar a interpretação visual da relação entre as incidências em homens e mulheres, dada a assimetria da distribuição dos potenciais valores da razão de incidências.

Os dados são apresentados em figuras em três eixos ortogonais entre si, produzidas com o software SAS 6.12 for Windows, subprogramas Proc G3GRID e Proc G3D (SAS Institute Inc., 1990). As variáveis representadas nos eixos da base são idade (faixas unitárias de 0 a 90 anos) e ano calendário (de 1979 a 1998). No eixo vertical são representados o número de óbitos, a incidência e o logaritmo do risco relativo, em função das variáveis da base.

A distribuição da população da RMSP nos anos 1980, 1991 e 1996 foi obtida consultandose os resultados do Censo 1980 (IBGE, 1983), Censo 1991 (IBGE, 1994) e Contagem Populacional 1996 (IBGE, 1997). A distribuição da população nos anos intercensitários (estimada por interpolação e projeção geométrica), bem como dos óbitos por causas externas específicas, segundo sexo e faixas etárias unitárias de 0 a 90 anos, na região e período estudados, foram diretamente obtidas da Fundação Sistema Estadual de Análise de Dados (Fundação SEADE, 1999).

\section{Resultados}

A proporção de incidência de óbitos por homicídios no sexo masculino cresceu de 35 para 121 (x 10-5) na Grande São Paulo nos últimos vinte anos. São apresentadas sete figuras que, em seu conjunto, situam a evolução deste fenômeno. As Figuras 1a, 2a e 3a representam, por diferentes ângulos e distâncias, a distribuição de homicídios masculinos, segundo idade, na região e período estudados. As Figuras 1b, $2 \mathrm{~b}$ e $3 \mathrm{~b}$ são, respectivamente, análogas às anteriores, mostrando a incidência de homicídios masculinos, segundo idade, na mesma região e período. A Figura 4 é uma superfície representando o logaritmo natural do risco relativo masculino/feminino para óbitos por homicídios estendidos segundo idade, na região e período estudados.

\section{Discussão}

A sofisticação crescente das análises quantitativas em epidemiologia nas últimas décadas tem deixado de lado um instrumento valioso na interpretação de informações em saúde: o olhar. Perdeu-se o hábito de analisar visualmente a distribuição da doença, da morte ou qualquer outro fenômeno de interesse epidemiológico. Contrapondo-se a esta tendência, este estudo busca enfatizar a relevância da análise visual no arsenal analítico epidemiológico. As figuras apresentadas neste trabalho sintetizam de forma dramática questões que têm sido levantadas por muitos pesquisadores nos últimos anos. São, na verdade, um instrumento a mais para auxiliar a compreensão dos homicídios.

O simples olhar para as Figuras 1a, 2a e 3a permite abstrair as principais características da evolução da mortalidade por homicídios 
Figura 1a

Distribuição de homicídios masculinos segundo idade e ano.

Região Metropolitana de São Paulo, Brasil, 1979-1998.

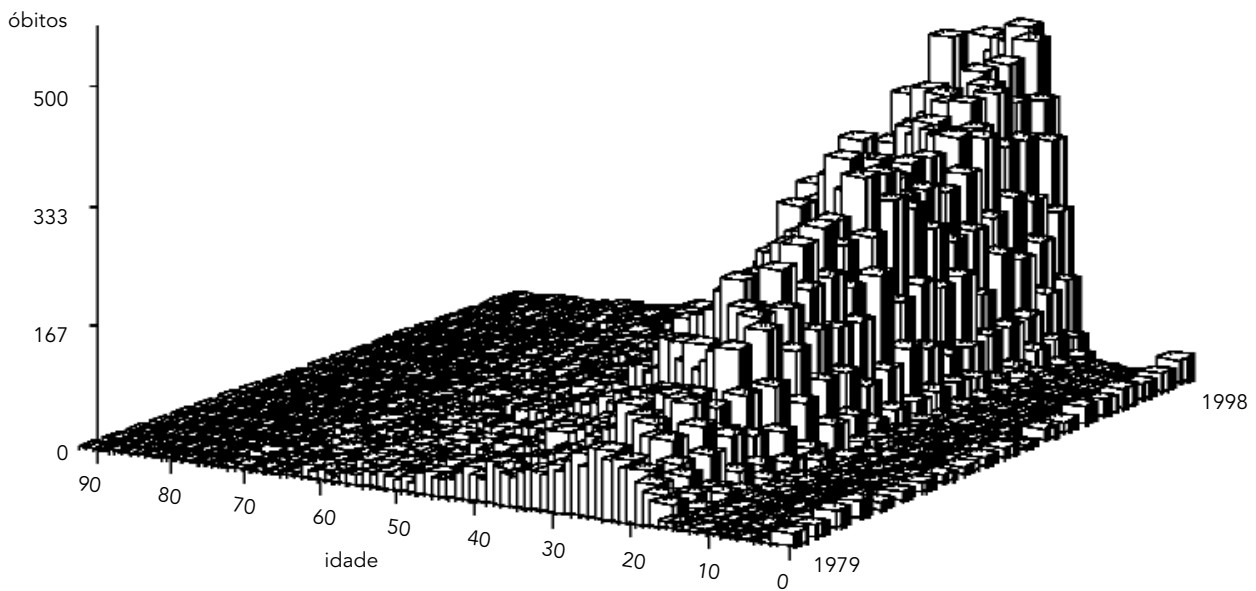

Figura $1 b$

Incidência de homicídios masculinos (x 10-5) segundo idade e ano.

Região Metropolitana de São Paulo, Brasil, 1979-1998.

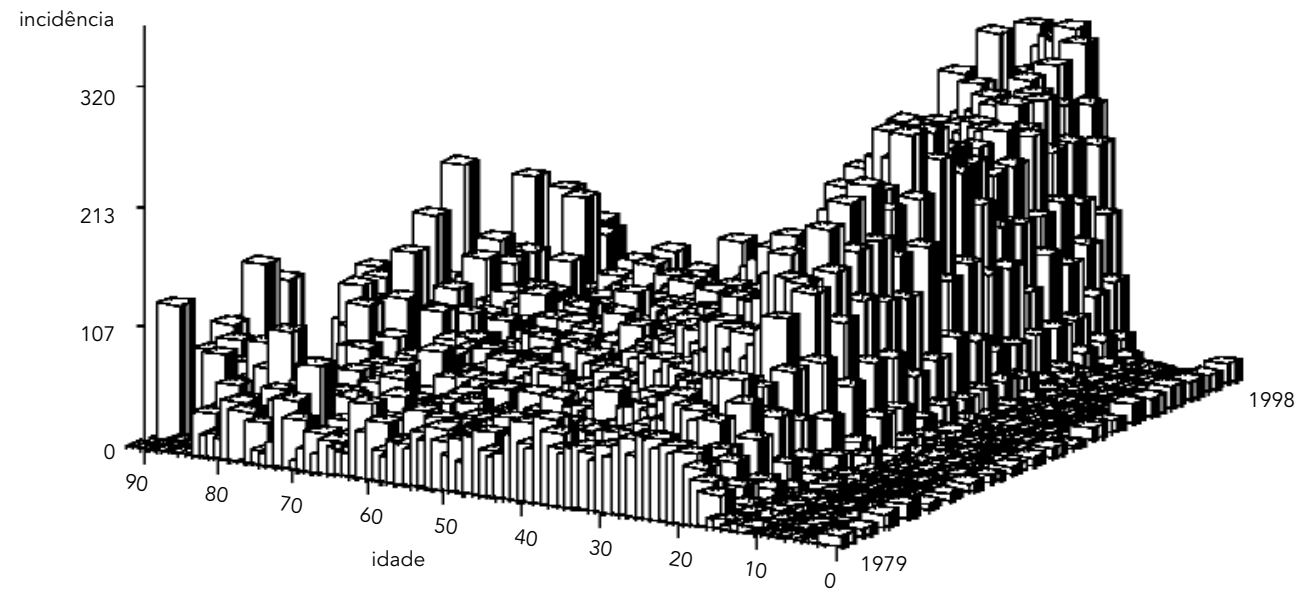


Figura 2a

Distribuição de homicídios masculinos segundo idade e ano.

Região Metropolitana de São Paulo, Brasil, 1979-1998.

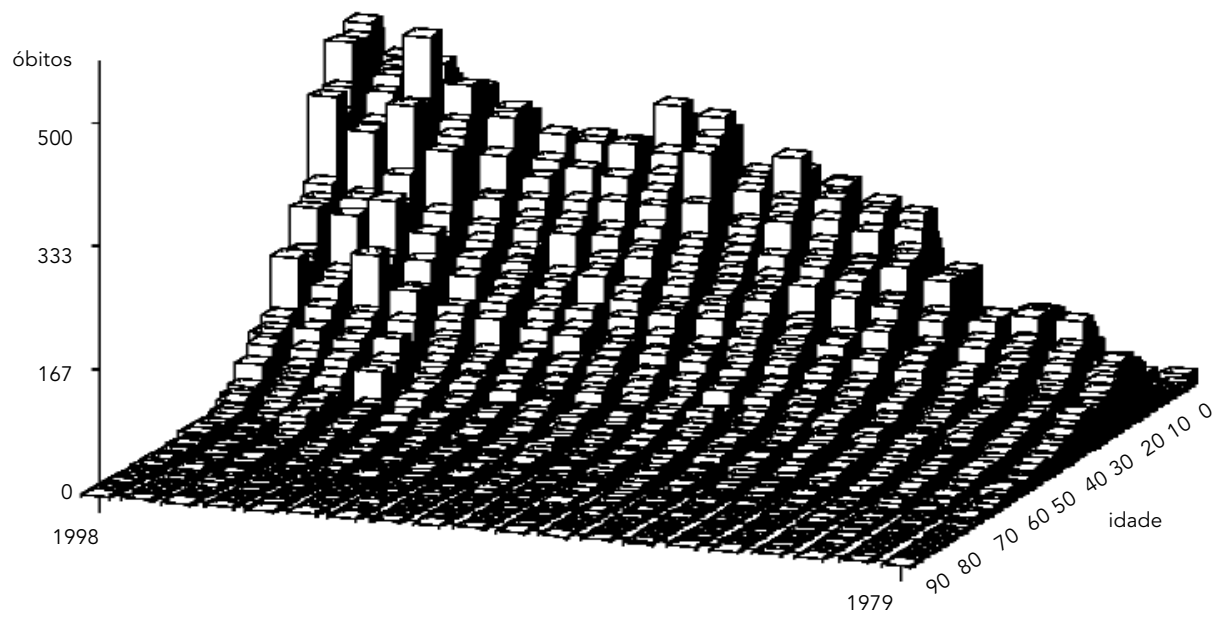

Figura $2 b$

Incidência de homicídios masculinos (x 10-5) segundo idade e ano.

Região Metropolitana de São Paulo, Brasil, 1979-1998.

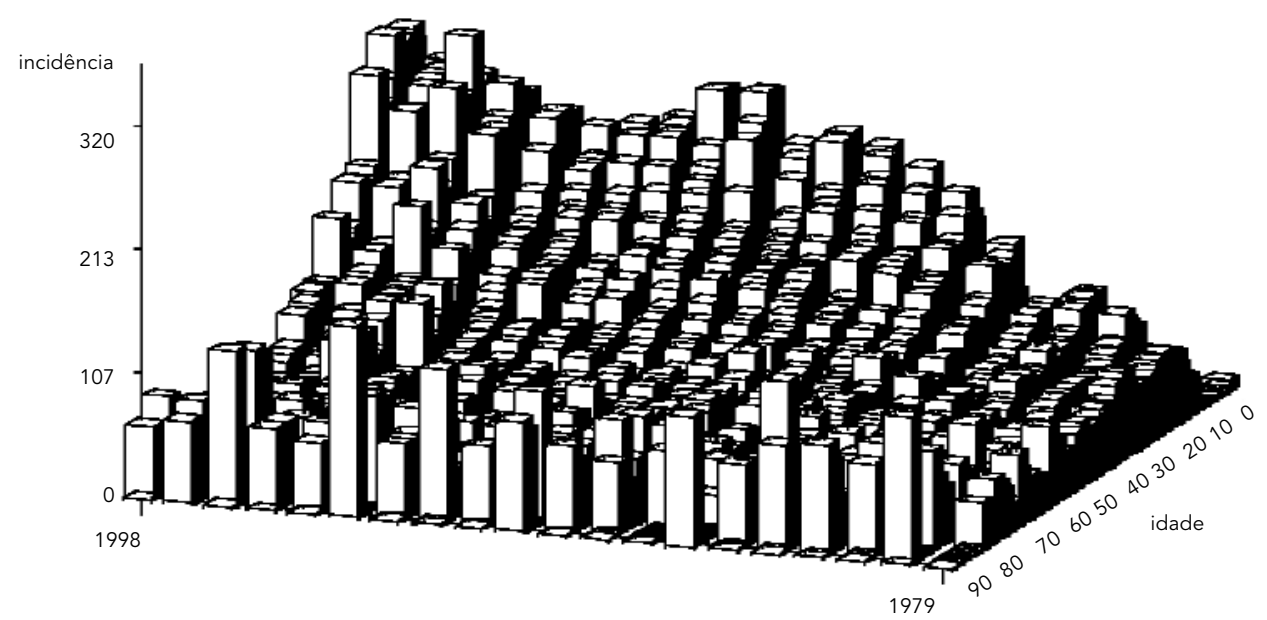


Figura 3a

Distribuição de homicídios masculinos segundo idade e ano.

Região Metropolitana de São Paulo, Brasil, 1979-1998.

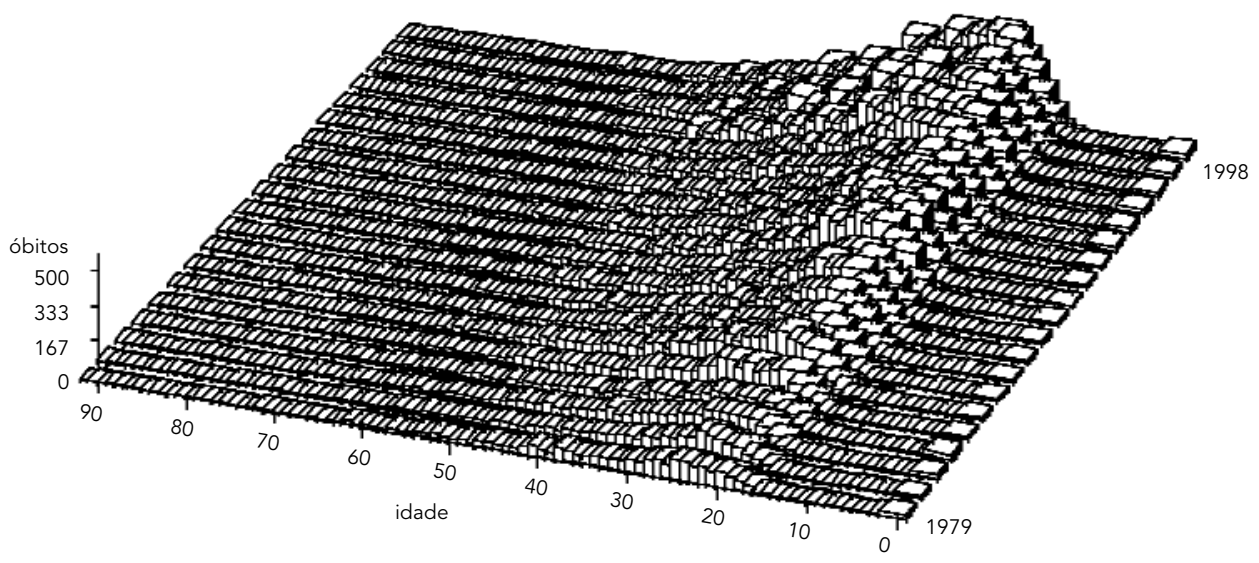

Figura $3 b$

Incidência de homicídios masculinos (x 10-5) segundo idade e ano.

Região Metropolitana de São Paulo, Brasil, 1979-1998.

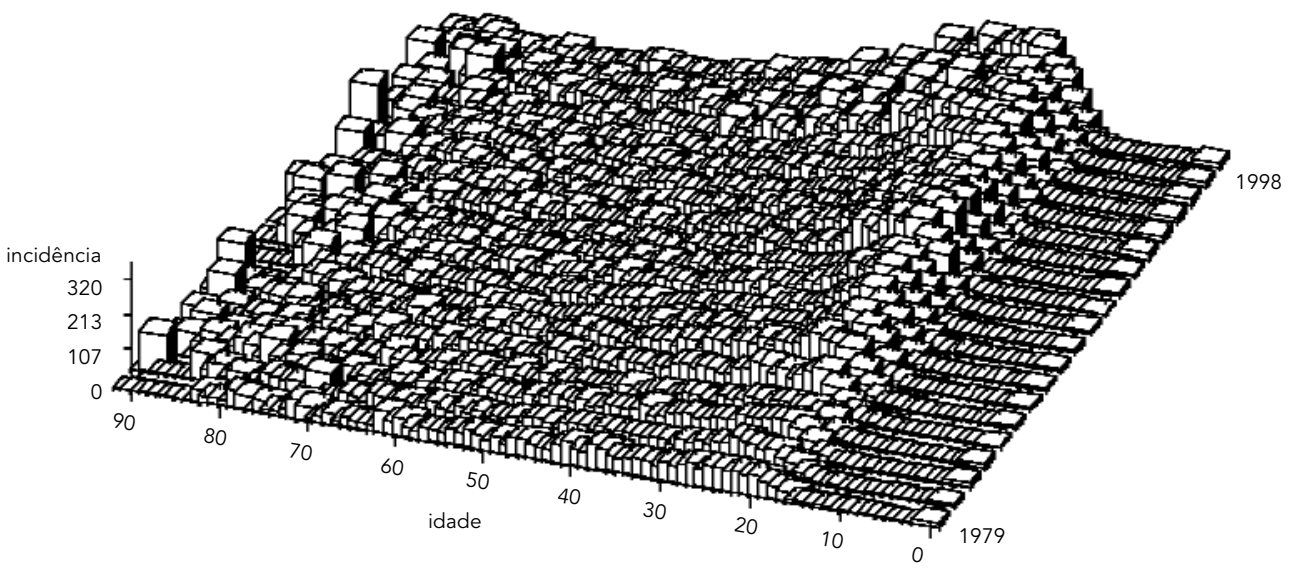




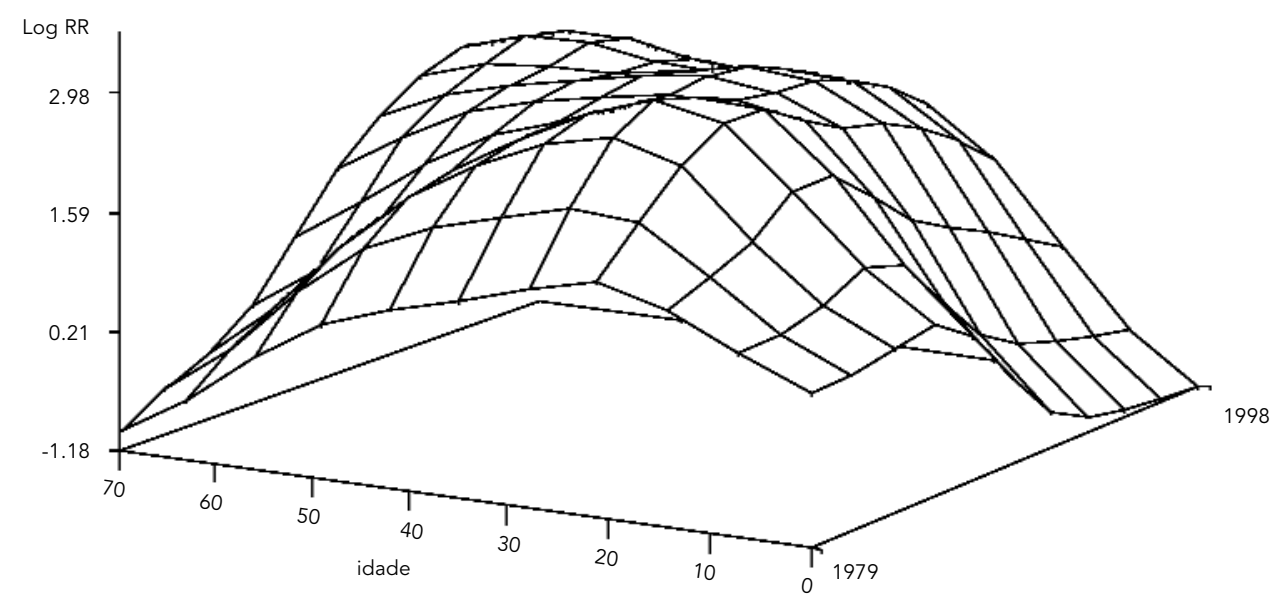

entre homens na RMSP nos últimos vinte anos. Percebe-se que se trata de um fenômeno:

- que predomina entre adolescentes e adultos jovens, sendo particularmente notável o aumento brusco a partir dos 14 anos;

- que vem aumentando consistente e acentuadamente ano a ano;

- e cujos limites vêm se espraiando tanto para as menores idades (abaixo dos 18 anos) como, e principalmente, para as maiores (acima dos 30 anos), com o passar do tempo.

Tais características podem também ser inferidas a partir da observação das Figuras 1b, 2 b e $3 b$. Entretanto, estas imagens não permitem concluir, como sugere o conjunto anterior de figuras, que os homicídios restringem-se exclusivamente às populações jovens. A partir da quarta década, a incidência parece diminuir o ritmo em que vinha caindo após ter atingido seu pico em meados da segunda década, mantendo-se em níveis preocupantes e chegando mesmo a aumentar sua magnitude nas faixas de idade mais avançadas. Isto ocorre porque, diferentemente do primeiro conjunto de figuras, que mostra número absoluto de homicídios em função de idade e ano de ocorrência, no segundo a variável distribuída é a proporção de incidência desses homicídios, uma razão do tipo a/ $(a+b)$. As Figuras 1a, 2a e 3a podem ser interpretadas como sendo os corpos empilhados dos moradores assassinados, espacialmente distribuídos de acordo com a idade da vítima e o ano da ocorrência do óbito. Já as Figuras 1b, 2b e 3b mostram uma construção teórica, uma abstração, que é o número de homicídios de fato ocorrido ponderado pela população exposta. Como, a partir da quarta década, a base populacional que origina os homicídios diminui mais intensamente que o número absoluto de homicídios, a incidência desacelera a queda que vinha apresentando, chegando mesmo a aumentar, sinalizando que o risco de homicídios aumentou a partir desta idade no período estudado. Entretanto, é importante observar que a incidência se apresenta instável a partir dos oitenta anos, alternando valores nulos com valores elevados, possivelmente em virtude do (relativo) pequeno número de indivíduos e óbitos no topo da pirâmide etária.

A Figura 4 compara graficamente o fenômeno entre homens e mulheres, salientando que o risco de homicídio entre homens em relação às mulheres aumenta a partir do nascimento, estabilizando-se em torno da metade da segunda década. Observa-se também nesta figura que esses valores têm aumentado no sentido crescente do eixo calendário (por exemplo, em 1979 o risco relativo era 5,3, passando a 22,6 em 1998), sugerindo uma intensificação do risco de homicídios no sexo masculino em relação ao feminino no decorrer das últimas duas décadas na região estudada.

Não se aplicam intervalos de confiança às incidências aqui apresentadas, uma vez que 
não se trabalhou com amostras, mas sim com o universo de óbitos da região estudada. Neste estudo, a incidência e o número absoluto de óbitos são duas medidas distintas da ocorrência de homicídios, com importância semelhante mas implicações diversas. Em epidemiologia, a incidência é uma medida de excelência. Noticia o fluxo de ocorrência de um fenômeno em um conjunto socialmente definido, sinalizando risco. A noção de que a incidência de homicídios continua alta, além da quarta década, na RMSP traz um elemento importante para o entendimento global do fenômeno, implicando na necessidade de medidas de prevenção específicas. Entretanto, há situações em que não apenas se deseja estimar riscos, mas também dimensionar o impacto imediato

\section{Agradecimentos}

À Fundação Sistema Estadual de Análise de Dados (Fundação SEADE), pelo fornecimento de dados para a elaboração deste trabalho, e à Fundação de Amparo à Pesquisa do Estado de São Paulo, pelo financiamento parcial deste estudo (processo FAPESP 99/03437-1). do fenômeno estudado. Números absolutos satisfazem essa necessidade, pois têm impacto direto e implicações imediatas. Eles são essenciais, por exemplo, para se dimensionar a clientela potencial de um programa específico ou para previsões de gastos em uma rede de saúde. No presente caso, os números absolutos noticiam, entre outras coisas, que é cada vez maior o número de assassinatos na RMSP, chegando à média de trinta pessoas a cada dia no ano de 1998. Independente de quaisquer outras considerações, sejam elas de que natureza forem, esses números chamam a atenção para a imperiosa e imediata necessidade (que transcende em muito os limites da epidemiologia) de reverter este quadro.

\section{Referências}

FUNDAÇÃO SEADE (Fundação Sistema Estadual de Análise de Dados), 1999. População Residente e Óbitos por Causa Externa Especificada, Segundo Idade Simples e Sexo na Região Metropolitana de São Paulo entre 1979 e 1998. São Paulo: Fundação SEADE. (mimeo.)

GRAUNT, J., 1939. Natural and Political Observation Made upon the Bills of Mortality, London, 1662. Baltimore: John Hopkins Press.

GREEN, M. S. \& SILVERMAN, B. W., 1994. Non-parametric Regression and Generalized Linear Models. New York: Chapman and Hall.

IBGE (Fundação Instituto Brasileiro de Geografia e Estatística), 1983. Censo Demográfico: Mão de Obra; São Paulo. Rio de Janeiro: IBGE.

IBGE (Fundação Instituto Brasileiro de Geografia e Estatística), 1994. Censo Demográfico 1991. Resultados do Universo Relativos às Características da População e dos Domicílios, no 21, São Paulo. Rio de Janeiro: IBGE.

IBGE (Fundação Instituto Brasileiro de Geografia e Estatística), 1997. Contagem da População, 1996. Rio de Janeiro: IBGE. 
IUNES, R. F., 1997. Impacto econômico das causas externas no Brasil: Um esforço de mensuração. $R e$ vista de Saúde Pública, 31:38-46.

LOPES, A. D., 1993. Causes of death in industrial and developing countries: Estimates for 1985-1990. In: Diseases Control Priorities in Developing Countries (World Bank, ed.), pp. 12-19, New York: Oxford University Press.

MELLO-JORGE, M. H. P., 1990. Situação atual das estatísticas oficiais relativas à mortalidade por causas externas. Revista de Saúde Pública, 24:217223.

MELLO-JORGE, M. H. P.; GAWRYSZEWSKI, V. P. \& LATORRE, M. R. D. O., 1997. Análise de dados de mortalidade. Revista de Saúde Pública, 31:5-25

MELLO-JORGE, M. H. P. \& LAURENTI. R., 1997. Apresentação. Revista de Saúde Pública, 31:1-4.

MINAYO, M. C. S., 1994. A violência social sob a perspectiva da saúde pública. Cadernos de Saúde Pública, 10:7-18.

MINAYO, M. C. S. \& SOUZA, E. R., 1993. Violência para todos. Cadernos de Saúde Pública, 9:65-78.

MS (Ministério da Saúde), 1997. Sistema de Informação sobre Mortalidade. Brasília: MS.
OMS (Organização Mundial de Saúde), 1985. Manual da Classificação Estatística Internacional de Doenças, Lesões e Causas de Óbito - Nona Conferência de Revisão. São Paulo: Centro Brasileiro de Classificação de Doença em Português.

OMS (Organização Mundial de Saúde), 1994. CID-10 Classificação Estatística Internacional de Doenças e Problemas Relacionados à Saúde - Décima Revisão. v. 2. São Paulo: Edusp.

REICHENHEIM, M. E. \& WERNECK, G. L., 1994. Anos potenciais de vida perdidos no Rio de Janeiro, 1990. As mortes violentas em questão. Cadernos de Saúde Pública, 10:188-198.

ROTHMAN, K. J. \& GREENLAND, S., 1998. Modern Epidemiology. Philadelphia: Lippincott-Raven.

SAS INSTITUTE INC., 1990. SAS/GRAPH Software: Reference. Cary: SAS Institute Inc.

SOUZA, E. R. \& MINAYO, M. C. S., 1995. O impacto da violência social na saúde pública no Brasil: Década de 80. In: Os Muitos Brasis - Saúde e População na Década de 80 (M. C. S. Minayo, org.), pp. 87 116, São Paulo: Editora Hucitec/ABRASCO.

SZWARCWALD, C. L. \& CASTILHO, E. A., 1998. Mortalidade por armas de fogo no Estado do Rio de Janeiro, Brasil: Uma análise espacial. Revista Panamericana de Salud Pública, 4:161-170. 